\title{
REFLEXÕES SOBRE A UNIÃO POLIAFETIVA: NOTAS SOBRE A FORMAÇÃO DA SUBJETIVIDADE
}

\author{
${ }^{1}$ Luciana Costa Poli \\ ${ }^{2}$ Bruno Ferraz Hazan
}

\begin{abstract}
RESUMO
$\mathrm{O}$ artigo relata um caso de três indivíduos que vivem uma união poliafetiva e procuraram um cartório para a lavratura de escritura pública de convivência. O estudo apresenta a ideia de gênero na concepção de Judith Butler e revela a importância de suas contribuições para a análise crítica da polêmica gerada pelo assunto. Examina ainda as múltiplas acepções ínsitas à subjetividade e seus reflexos sobre a eleição do núcleo familiar. Por fim, o trabalho questiona a necessidade de regulamentação da união poliafetiva e os desafios do direito contemporâneo para atender de forma igualitária as demandas de todos os núcleos familiares.
\end{abstract}

Palavras-chave: União poliafetiva, Subjetividade, Gênero

\section{REFLEXIONES SOBRE LA UNIÓN POLIAFECTIVA: NOTAS SOBRE LA FORMACIÓN DE LA SUBJETIVIDAD}

\section{RESUMEN}

El artículo describe un caso de tres personas que viven una unión poliafectiva y buscaran perante el Notario la elaboración de escritura de la convivencia. El artículo presenta la idea de género en Judith Butler y demuestra la importancia de sus contribuciones a la revisión de la polémica generada por el tema. Examina los diversos significados inherentes a la subjetividad y su impacto en la elección del núcleo familiar. Por último, el trabajo cuestiona la necesidad de la regulación de la unión poliafectiva y los desafíos del derecho contemporáneo para satisfacer por igual las necesidades de todas las familias.

Palabras-claves: Unión poliafectiva, Subjetividad, Género

\footnotetext{
1 Doutora em Direito pela Pontifícia Universidade Católica de Minas Gerais - PUC/MG, Minas Gerais. (Brasil). Professora da Pontifícia Universidade Católica de Minas Gerais - PUC/MG, Minas Gerais. (Brasil). E-mail: lucostapoli@yahoo.com.br

2 Doutorando em Direito Privado pela Pontifícia Universidade Católica de Minas Gerais - PUC/MG, Minas Gerais. (Brasil). E-mail: bruno.hazan@gmail.com
} 
O senhor... mire, veja: o mais importante e bonito, do mundo, é isto: que as pessoas não estão sempre iguais, ainda não foram terminadas - mas que elas vão sempre mudando. Afinam ou desafinam, verdade maior. É o que a vida me ensinou. Isso que me alegra montão. (Guimarães Rosa, 1956, Grande Sertão Veredas)

\section{INTRODUÇÃO}

As reflexões ora propostas se inspiraram em um caso real ocorrido no ano de 2015 no Brasil. Trata-se do relato referente a três mulheres que conseguiram, no Estado do Rio de Janeiro, lavrar em cartório uma escritura pública de convivência com o objetivo de oficializar uma relação amorosa. Essa notícia causou alvoroço na mídia nacional e internacional ${ }^{1}$, embora seja o segundo trio já registrado no Brasil. O primeiro caso noticiado ocorreu em Tupã, Estado de São Paulo, entre um homem e duas mulheres.

A esses enlaces, que unem mais de duas pessoas, convencionou-se chamar união poliafetiva estável. O debate sobre poliamor, embora ainda fora das estatísticas, é uma questão presente em várias capitais do Brasil, onde grupos, festas e atividades são formados por meio de redes sociais. No Rio de Janeiro, por exemplo, a apelidada reunião Poliencontro discute novas formas de compreender as relações amorosas entre mais de duas pessoas e ocupa uma dúzia de edições, com eventos em espaços públicos da cidade.

No caso do Rio de Janeiro, o documento firmado pelas partes revela a intenção de serem reconhecidas como núcleo familiar, com a pretensão de garantir a separação de bens e atribuir a cada uma a possibilidade de decisão sobre questões médicas das demais. A tabeliã que lavrou a escritura, em entrevista, asseverou não ter encontrado óbice na legislação brasileira a impedir a realização do documento, embora tenha reconhecido que este não garante direitos familiares ou sucessórios - direitos que deverão ser pleiteados perante o Poder Judiciário. Segundo a tabeliã, os fundamentos que ampararam a decisão do Supremo Tribunal Federal que reconheceu, em 2011, aos casais do mesmo sexo os efeitos da união estável, são os mesmos que possibilitariam a união poliafetiva ${ }^{2}$.

\footnotetext{
1 http://www.pragmatismopolitico.com.br/2015/10/a-primeira-uniao-estavel-realizada-entre-tres-mulheres-nobrasil.html; http://g1.globo.com/sp/bauru-marilia/noticia/2012/08/união-estável-entre-tres-pessoaseoficializadaem-cartorio-de-tupa-sp.html.

${ }^{2}$ O Plenário do Supremo Tribunal Federal realizou, no dia 5 de maio de 2011, o julgamento conjunto da Ação Direta de Inconstitucionalidade n. 4277 e da Arguição de Descumprimento de Preceito Fundamental n. 132, em que se discutiu a equiparação da união estável entre pessoas do mesmo sexo à entidade familiar, preconizada pelo artigo 1.723 do Código Civil, desde que preenchidos requisitos semelhantes, dando interpretação a este conforme a Constituição da República Federativa do Brasil.
} 
As possíveis questões jurídicas que permeiam o tema são vastas, mas dados os limites do trabalho, realizou-se um pequeno recorte temático. Assim o artigo abordará brevemente os estudos acerca do gênero elaborados por Judith Butler, além da contribuição psicanalítica de Foucault. Pretende-se mostrar ainda que as uniões poliafetivas refletem, de certa forma, subjetividades emergentes que escapam a padronizações e desafiam o direito pelo descortinar de realidades familiares até então escondidas, instigando ao estudo de outras disciplinas como a psicologia e as ciências sociais.

\section{UNIÃO POLIAFETIVA: NOTÍCIAS E INDAGAÇÕES ENTRE CANAdÁ E ESPANHA}

De toda sorte, o episódio relatado reacendeu a polêmica acerca da possibilidade ou não de reconhecimento jurídico de efeitos a uniões constituídas por mais de duas pessoas, uma realidade que se abre ao público e inicia um caminho de reinvindicações e conquistas jurídicas e sociais.

O termo "poliamorismo ou poliamor, teoria psicológica que começa a descortinar-se para o Direito, admite a possibilidade de coexistirem duas ou mais relações afetivas paralelas, em que os seus partícipes conhecem e aceitam uns aos outros, em uma relação múltipla e aberta" (GAGLIANO, 2008).

União poliafetiva plúrima, paralelismo afetivo, poliafeto ou poliamorismo, são termos que buscam definir um mesmo fenômeno social: a existência de vínculo afetivo entre três ou mais pessoas, que formam uma unidade familiar, engendrada no suposto afeto entre seus participes.

Certo é que o modelo tradicional de família constituída pelo casamento com filhos há anos não é majoritário nos cinquenta e sete milhões de lares do Brasil ${ }^{3}$. Molduras familiares de diferentes matizes (mães solteiras, pais que cuidam sozinhos de seus filhos, casamentos sem filhos, uniões homossexuais, dentre outras) representam a realidade de $56,1 \%$ dos domicílios brasileiros.

No Canadá dois rapazes, que já eram casados ${ }^{4}$, divorciaram-se não com o intuito de romperem a relação, mas de incluir um terceiro parceiro à família ${ }^{5}$. Todos dividem o mesmo

\footnotetext{
${ }^{3}$ Enquanto $75 \%$ dos lares eram formados por casais com filhos em 1980, esse número caiu para 43,9\% em 2013. Atrás da opção pelo casamento tradicional aparecem os casais sem filhos $(19,4 \%)$ e os lares com mulheres solteiras com filhos (16,5\%). Dados de 2013 do Instituto Brasileiro de Geografia e Estatística (IBGE).

4 O Canadá permite o matrimônio igualitário há mais de uma década.

${ }^{5}$ Adam Grant (27 anos) e Shayne Curran (29 anos), um casal de jovens residentes na província canadense de Nova Escócia decidiu se divorciar para incluírem em sua relação, em igualdade de condições, Sebastian Tran, de 29 anos.
} 
teto e estudam ter um filho com a ajuda de suas irmãs - uma funcionaria como mãe solidária e a outra seria a doadora do óvulo ${ }^{6}$. O trio avalia, com a ajuda de advogados, que tipo de vínculo legal de caráter privado poderia estabelecer entre seus membros, já que o Canadá, até o momento, não reconhece este tipo de tríade familiar ${ }^{7}$.

Esse tipo de notícia gera cada vez mais polêmica. Se, por um lado, trata-se de reconhecer modelos familiares que ultrapassam os tradicionalmente aceitos, por outro não faltarão os que tentarão utilizar tais notícias para justificar sua oposição, argumentando a possibilidade de abertura à temida poligamia. Outros, ainda, mostrar-se-ão simplesmente espantados diante daquilo que consideram uma banalização das relações afetivas e da parentalidade. Não há dúvidas, porém, que a sociedade se encontra diante de uma realidade emergente e, possivelmente, não tão marginal. Seria a união poliafetiva uma nova forma de organização familiar ou apenas uma das facetas da já reconhecida união estável, cujos efeitos foram estendidos pelo Supremo Tribunal Federal às uniões homoafetivas? Estaria o conceito de família, mais uma vez, ameaçado? E qual seria o seu alcance?

Indaga-se, também, se na Espanha seria possível uma situação similar, considerando a legislação vigente em matéria de uniões estáveis, já que um dos argumentos que utiliza a tabeliã brasileira é que não há proibição no ordenamento jurídico para a lavratura de escritura pública nestes termos.

Não obstante, para a valoração de tal possibilidade no ordenamento jurídico espanhol, deve-se considerar que como não há uma legislação estatal em matéria de uniões estáveis, as diferentes legislações autônomas aprovadas sobre o tema precisam ser observadas, o que implica em reconhecer que, de fato, há comunidades autônomas sem qualquer regulação a esse respeito.

Como referência, a título ilustrativo, tome-se a legislação catalã sobre o assunto. A Catalunha foi a primeira comunidade autônoma espanhola que regulamentou a união estável, pela já revogada Lei 10/1998 (Ley de Uniones Estables de Pareja). Segundo as regras atuais, seria difícil reconhecer juridicamente a união poliafetiva, já que o artigo 234-1 do Código Civil da Catalunha dispõe: "duas pessoas que vivem em uma comunidade semelhante à vida de casada [...]". Nesse caso, aos olhos da legislação catalã, a parceria estável só poderia ser constituída por duas pessoas. Portanto, a conclusão parece, à primeira vista, clara: a união poliafetiva não poderia ser considerada união estável.

\footnotetext{
${ }^{6} \mathrm{http} / / /$ www.dosmanzanas.com/2015/10/relaciones-poliafectivas-una-realidad-que-se-abre-paso.html.

7 Ainda que o Canadá se apresente como um dos países mais vanguardistas em relação ao reconhecimento de novos modelos familiares. Já em 2007, por exemplo, um tribunal de Ontário reconheceu como pais de garoto em igualdade de condições três pessoas: os pais biológicos e a companheira sentimental de sua mãe. Permite-se também no país a gestação de aluguel ou subrogada sempre que não exista interesse econômico.
} 
Mas, embora a literalidade do artigo 234-1 da legislação cível catalã dite "duas pessoas", também é verdade que não há na legislação a proibição de outras uniões. Assim, seguindo o argumento da Notária brasileira e o axioma "o que não é proibido é permitido", a união poliafetiva poderia dar-se no Direito catalão.

Também se deve ter em mente que o segundo livro do Código Civil da Catalunha rege a assistência mútua nas situações de convívio, o que poderia ser uma brecha apta a albergar a união poliafetiva. A título de exemplo, pode-se imaginar três pessoas que vivem juntas apenas para compartilhar o apartamento, por motivos profissionais, unidas por um vínculo de amizade. Nos termos do artigo 240-3 do Código Civil da Catalunha, depois de dois anos de convivência estabelece-se uma relação de convívio assistência mútua. Seria então possível assimilar a relação de convívio de união poliafetiva como ajuda mútua?

Essas são apenas algumas considerações iniciais, a fim de suscitar questionamentos. Um estudo mais aprofundado da legislação e doutrina espanholas seria necessário para uma conclusão mais definitiva, o que não é o foco do trabalho.

\section{RETRATOS DA FAMÍLIA CONTEMPORÂNEA: DESCORTINANDO INVISIBILIDADES}

Manusear álbuns de família é uma experiência reveladora: são registros de moda, de hábitos culinários, de brincadeiras, de formas de conduta, de postura, de costumes e, sobretudo, para um olhar um pouco mais arguto, de distinções hierárquicas.

Nas fotos mais antigas, nos antepassados mais remotos, distingue-se logo a figura do patriarca, centrado, sisudo, compenetrado que, em geral, se posta de pé cercado dos filhos, tendo ao seu lado os mais velhos e, ao fundo, ou cuidadosamente sentados e arrumados, os netos. A esposa e as demais mulheres buscam resguardar nos olhos o respeito, obediência e quase veneração à figura central a quem devem agradecer permanentemente a subsistência e a possiblidade de alcançarem a graça de serem mães.

Os homens preservam o olhar agudo, símbolo da responsabilidade pelo sustento material da família, as mulheres entre docilidade e submissão revelam uma vida dedicada às tarefas do lar e à educação dos filhos. As casadas, cumprido seu objetivo maior, podem dedicar-se à preparação das mais jovens: a busca por um casamento conveniente que lhes proporcione estabilidade e status social. Essa família, voltada à tradição procriativa e às alianças para estreitar os laços biológicos ou favorecer o acúmulo patrimonial, é hierarquizada, monolítica, horizontal. Prescreve códigos de conduta, repudia as diferenças, mascara e esconde realidades. 
Voltam-se esses indivíduos à proteção e salvaguarda da instituição. A família representada pelo casamento e pelos laços de sangue há que ser mantida. Sacrifícios, amores partidos, filhos bastados abandonados, traições, tudo vale para se manter a unidade.

As fotos de família atuais causariam estranhamento a qualquer distinto cidadão do início do século passado. Vê-se uma mulher cercada por seus dois filhos, frutos de inseminação artificial, em outra foto, dois homens disfrutam de uma risada matinal à mesa do café da manhã, cercados por seus cães. Em um terceiro retrato, um casal divide a cena com dois adolescentes filhos de uma relação anterior e os dois bebês havidos há poucos meses antes da cerimônia de casamento. Há ainda fotos daqueles que decidiram viver em casas separadas, do casal que conheceu uma moça na praia e está com ela até hoje. Das amigas que se tornaram amantes, companheiras.

Enfim, em poucos anos, considerando a história da humanidade, o panorama familiar descortinou-se. As mulheres alcançaram a tão almejada igualdade, obtiveram oportunidades de independência econômica, os filhos primogênitos perderam o protagonismo, a perenidade do casamento desapareceu, a família não é mais sinônimo de casamento.

Começa a mostrar a multiplicidade de arranjos familiares, o prestígio alcançado pelas crianças, seres até então sem voz, entregues aos cuidados das amas, cunhãs, isoladas do convívio dos adultos, passam a ter interesses tutelados, participam como protagonistas do núcleo familiar, desafiam autoridade, clamam por direitos, exigem participação. As configurações familiares atuais denotam a riqueza da diversidade, rompem com tradições morais, buscam a satisfação de desejos/necessidades, redefinem papéis e funções e pretendem satisfazer o afã por afeto. O termo família não mais simboliza a síntese de todas as convenções características de uma sociedade patriarcal.

A leitura dos extratos de notícias sobre os casos relatados, de conteúdo jornalístico ou jurídico, revelam a ênfase conferida ao sexo dos indivíduos que pleitearam a lavratura das escrituras das uniões poliafetivas. No trio do Rio de Janeiro, anteriormente relatado, a notícia pareceu ainda mais sensacionalista por tratar-se de três mulheres. Esses registros demonstram como a sociedade e o Direito ainda atribuem diferenciações decorrentes do gênero ou do sexo.

\subsection{Gênero: noções introdutórias}

Não raras as vezes, os conceitos de gênero e sexo são tratados como sinônimos tanto na linguagem comum como na acadêmica. Certamente, gênero é um conceito de difícil compreensão, dadas as constantes resignações que lhe são atribuídas ao longo do percurso 
histórico, principalmente após os estudos de grandes pensadores que se debruçaram sobre os movimentos feministas. Tenta-se esclarecer algumas noções sobre o tema, com amparo na contribuição dos estudos feministas ${ }^{8}$ e, sobretudo, na obra de Judith Butler.

A origem etimológica da palavra encontra-se no vocábulo latim genus (AYTO, 1990). Relata Germon (2009) que na década de 1950 seu uso ganhou força na língua inglesa entre os acadêmicos, graças ao trabalho de John Money ${ }^{9}$ que o definiu como uma categoria pessoal e social, um instrumento conceitual para entender a subjetividade humana como masculina e feminina e para formular suas teorias sobre os casos das pessoas intersexo (hermafroditas). Recusava Money o dualismo cartesiano, assentado nas distinções sexo/gênero e natureza/cultura. Em sua obra, sugeriu que o gênero seria produzido pela interação entre os aspectos corporal, sensorial e social, portanto, uma dimensão do erotismo e uma aprendizagem historicamente relativa. Outros médicos e psicanalistas, a exemplo Robert Stoller, em sua pesquisa sobre o transexualismo em meados da década de 1960 retrabalharam o tema, de forma a propor a distinção entre sexo (o elemento natural, material e carnal) de gênero (os elementos psíquicos e psicológicos). Suas proposições contribuíram para uma virada conceitual de forma a separar de modo mais definitivo sexo e gênero, excluindo-o de associações carnais e afastando-o da noção de luxúria (GERMON, 2009).

Segundo Germon (2009), para a grande massa, a ideia de gênero disseminou-se, ainda que de forma irregular, com o legado de Simone de Beauvoir e do feminismo, que utilizaram-se das contribuições de Money e Stoller. A apropriação do conceito pelas pensadoras do movimento feminista foi extremamente útil de forma a combater o uso tradicional e histórico do determinismo biológico para justificar a subordinação das mulheres, dadas suas características morfológicas (fragilidade muscular e capacidade reprodutiva) que as separavam dos homens no contexto da divisão sexual/social do trabalho.

Algum tempo depois, críticas feministas - o feminismo pós-estruturalista nas décadas de 1980 e 1990 - trataram de problematizar a própria lógica dualista: a dicotomia natureza/cultura (sexo/gênero). A compreensão, por esse movimento de sexo/corpo também como construções culturais e históricas, desafiou os contornos até então deflagrados pelo feminismo e sugeriu a imbricação entre corpo, sexo e gênero, inclusive postulando que não se concebe corpo sem sexo ou sexualidade sem gênero (CRANNY-FRANCIS et al., 2003).

\footnotetext{
${ }^{8}$ Para um estudo mais aprofundado sobre o impacto dos estudos feministas na questão do gênero, consultar Louro (1997) e Piscitelli (2002).

${ }^{9}$ Considerado o primeiro psicoendocrinologista clínico pediátrico do mundo, John Money desenvolveu sua carreira no Hospital e Escola de Medicina Johns Hopkins de 1951 a 2006; foi Professor Emérito de Psicologia Médica do Departamento de Psiquiatria e Ciências do Comportamento e Professor Emérito de Pediatria. Sobre a
} 
biografia de John Money, consultar: http://www.phs.umn.edu/newsletter/moneylecture/moneybio/home.html.

Antes do surgimento do termo "gênero", o termo "sexo" incluía as categorias biológica e social. Até a década de 1980, utilizava-se, no Brasil, o termo "relações sociais de sexo", por influência da literatura feminista francesa, ao invés de "relações de gênero". É possível que o termo gênero tenha se tornado um eufemismo para sexo, a fim de se evitar as conotações de genitália e coito.

\subsection{Gênero em Butler}

Judith Butler é um dos nomes mais contundentes sobre os estudos do gênero na contemporaneidade. Constrói suas ideias a partir de críticas das noções de gênero apropriadas pelas pensadoras feministas. Seria ingênuo dizer que rechaça o percurso histórico dos movimentos feministas, ao conferir pertinência politica e teórica ao gênero, mas, sem dúvida, empresta-lhe novas e inusitadas formas, compreendendo-lhe como um processo, dotado de dinamicidade ínsita, que não se conforma ou não se estabiliza. Seus trabalhos ultrapassam a noção de que o gênero é fruto das circunstâncias culturais, que é pré-estabelecido e estaria apenas sujeito a modulações circunstanciais. Pode-se afirmar que enuncia de forma radical suas potencialidades e, ao mesmo tempo, rechaça o fetiche e a divindade que tradicionalmente lhe são inerentes. Compreende o gênero como performance e não como atributo inato ou característico de determinado indivíduo.

Em sua elaboração teórica, a ideia de gênero aproxima-se do mecanismo ou aparato pelo qual "a normalização do masculino e do feminino se manifestam junto com as formas intersticiais, hormonais, cromossômicas, físicas e performáticas” (BUTLER, 2014, p. 250). Para a autora, há que se abandonar a composição binária e estática das matrizes "masculino" e "feminino", a fim de se compreender as permutações de gênero que não se encaixam na fórmula binária, que acaba por sufocar e esgotar em si mesma o campo de compreensão semântica do termo. Demonstra que a perspectiva teórica centrada no binarismo masculino e feminino esgota as possibilidades de extensão do campo semântico de gênero e possibilita que atue "no sentido de efetuar uma operação reguladora de poder que naturaliza a instância hegemônica e exclui a possibilidade de pensar sua disrupção” (BUTLER, 2014, p. 251).

A gramática de compreensão do gênero deve ultrapassar seu conteúdo de expressão normativa, a fim de se compreender que, ao mesmo tempo em que gênero é o mecanismo pelo qual as noções de masculino e feminino são produzidas e naturalizadas, pode funcionar

também como aparato para a desconstrução e desnaturalização desses termos. Assevera que a referência à "confusão de gênero", "mistura de gêneros", "transgêneros" ou "cross-gêneros" 
sugere que a expressão gênero se move muito além do binarismo naturalizado e hegemônico.

Por outro lado, a autora não defende que o contraponto ao binarismo deve supor multiplicação dos gêneros. Nesse ponto, recorre aos trabalhos de Luce Irigaray, que seguindo o pensamento lacaniano, acaba por afirmar que masculinidade ou feminilidade encontram-se na divisa entre o social e o biológico e não podem ser capturados por números (IRIGARAY, $1985)^{10}$.

Concordando ou não com os pensamentos de Butler, certo é que suas obras despontam pela capacidade de provocar um convite ao pensamento crítico, já que o modelo de performatividade utilizado para seus estudos sobre o gênero podem se aplicar facilmente a qualquer matriz de poder.

Retomando ao ponto central do trabalho, percebe-se que para o efetivo reconhecimento jurídico e social da multiplicidade de formas de família existentes, deve se desconectar dos imperativos que tradicionalmente enlaçam o direito de família e que foram erigidos na composição binária homem e mulher. A partir desse enfoque, a título exemplificativo, a justificativa para a ampliação de direitos e prerrogativas à união homoafetiva deve assentar-se nos direitos fundamentais (liberdade, igualdade, não discriminação), de forma a garantir que a esfera pública abrace de forma laica e abstrata os interesses de todos os indivíduos que se unem por quaisquer laços afetivos, inclusive àqueles que escapam a convenções seculares, sem qualquer menção à opção sexual ou diferenciações de gênero.

No caso do poliamorismo, a questão se coloca da mesma forma. Não há que se discutir ou sequer se mencionar o gênero dos envolvidos. A garantia de direitos e prerrogativas deve se afastar de qualquer juízo valorativo quanto à performance de gênero dos indivíduos envolvidos, o papel que exercem no núcleo familiar ou quaisquer outros arranjos de cunho íntimo que circundam a relação.

O arrimo a ser garantido pelo Direito deve ser objetivo de forma a possibilitar fruição dos direitos fundamentais do cidadão, desviando a discussão de qualquer curiosidade alheia sobre a dinâmica da relação escolhida pelos indivíduos.

\footnotetext{
${ }^{10} \mathrm{Na}$ mesma linha, Bornstein (1994), para quem o "transgênero" não se caracteriza por um terceiro gênero, mas representa um modo de passagem entre os gêneros, uma figura intersticial e transicional de gênero, que não é redutível à insistência normativa de um ou dois.
} 


\section{DA SUBJETIVIDADE EM MASSA À SUBJETIVIDADE EMERGENTE}

A importância desse estudo se revela na percepção que as relações poliafetivas sofrem rechaço de parte considerável da população, habituada ao toque tradicional e fortemente reproduzido de comportamentos e modos de vida. Isso indica que os signos individuais têm sido insistentemente apagados. Esse fenômeno acaba por repercutir na construção da subjetividade ínsita a cada indivíduo, que insuflado incessantemente pela violência da força da comunicação em massa, perde a capacidade de filtragem, essencial à elaboração de uma subjetividade única, distintiva, especial a cada um.

A subjetividade refere-se ao universo de ideias, significados e emoções moldado internamente pelo sujeito a partir de suas relações sociais, de suas vivências e de sua constituição biológica. Revela-se ainda como locus de suas manifestações afetivas e comportamentais. É o mundo interior, sujeito às influências e influxos constantes das experiências vivenciadas, da cultura, do modo de viver, das relações sociais (BIRMAN, 2000, p. 45). Mas, por outra faceta, a subjetividade também se mostra automoldável, ou seja, o próprio indivíduo deve ser capaz, paralelamente às influências externas, de promover novas formas de subjetividade, recusando-se ao ajustamento imposto pela massificação das informações, capaz de afugentar a possibilidade do afloramento de seus desejos íntimos, da formação de seu próprio e único juízo sobre as coisas e sobre seus sentimentos (CUNHA, 2002, p. 170).

O assujeitamento imposto pela massificação da informação conduz à perda da memória histórica individual, exclui e estigmatiza o diferente, condiciona a aceitação aos ditames do consumo, impede que a subjetividade se expresse de sua maneira mais peculiar que é a maneira de sentir, pensar, fantasiar, sonhar, amar e fazer de cada um (MOREIRA, 2009).

Por isso, a subjetividade é essencial à construção do destino de cada um e da própria coletividade (SARZ, 2009). Assim, não se alinha a padrões de produção, a moldes, a processos de captura e submissão, que tendem a mobilizar o indivíduo a pensar, agir e até mesmo sentir.

A subjetividade emergirá na escolha da forma de família, na qual o indivíduo se sinta acolhido, portanto, como elemento único e característico de cada um e revelará uma multiplicidade de espectros familiares. A união poliafetiva, de certa forma, espelha o oposto da subjetividade fabricada, enlatada, disponível para ser consumida, produzida em massa, fruto de um discurso que remete a enunciados de poder, que não permite individualizações e processos próprios de "fantasmização". 
A eleição de um núcleo poliafetivo corresponde, nessa linha, à consolidação de processos conducentes à emancipação ${ }^{11}$, à perseguição da expressão de uma identidade cultural e psíquica própria de cada um, que se revela pelo reconhecimento do inconsciente, da clivagem subjetiva. Dessa forma, a família há de ser vista não como uma massa heterogênea, um aglomerado, uma soma de individualidades aleatórias e não situadas, mas sim como um conjunto aberto, uma coleção de singularidades, em que cada membro é tomado em suas peculiaridades, um campo discursivo fértil em que se encadernam incontáveis significantes. Assim, no seio da família, aflora-se a constituição subjetiva que implica, de certa forma, uma realização de um desejo (LACAN, 1998, p. 56).

Não há como negar que o homem contemporâneo deve iniciar uma jornada de reflexões e questionamentos de forma a reconquistar estruturas que possibilitem o pleno desenvolvimento da personalidade e da subjetividade de cada um. Há que desvencilhar de tentativas de uniformização, independentemente de quem as impõe: o Estado, o consumismo, o modismo ou a religião.

Requer-se uma mudança de estado, já que os pilares da sociedade contemporânea ainda repousam na uniformização, marca fundamental do estado moderno, que nega sistematicamente a diversidade e outras formas de enxergar o mundo. Vive-se um momento de mudança de época e de crise das instituições modernas. Há quem ainda procura ocultar a diversidade para estabelecer-se um padrão, um arquétipo que se opera por um encobrimento de outras formas de pensar e compreender o mundo, na tentativa de fixar-se uma hegemonia filosófica e ideológica. A imposição da hegemonia abafa os costumes locais e encobre as diversidades sob um falso manto de proteção (museificação).

Por essa razão, a repercussão e as discussões que giram em torno do caso relatado no estudo contribuem para que no futuro exista o devido reconhecimento e consolidação de subjetividades, modos de vida e famílias diversas. O Direito deve se integrar por um processo de constituição contínua e dialética marcado pelas dimensões das realidades múltiplas (MOREIRA PINTO, 2004, p. 87).

\footnotetext{
${ }^{11}$ Apesar de a racionalidade ser uma característica essencial da natureza humana, que impulsiona ações individuais e sociais, compõe-se de significados diversos, sutis e implícitos, que influenciam e direcionam a visão de mundo da sociedade. A racionalidade emancipatória direciona-se pela capacidade de homens e mulheres deliberarem sobre as condições da sua própria existência opõe-se à racionalidade instrumental ou funcional, chamada por Santos (2000, p. 123) de indolente (leva em consideração o cálculo utilitário de consequências como única referência a guiar as ações dos indivíduos que adquirem um sentido de comportamento racional limitado).
} 


\section{ENTRE REGULAÇÃO E NÃO REGULAÇÃO: A DÚVIDA PERSISTE}

O que se sugere no texto é também uma reflexão acerca da ideia de regulação. Devem as uniões poliafetivas ser regulamentadas? Percebe-se que, de forma geral, há um afã pela manifestação regulatória do Estado, seja por normas, seja pela manifestação do Poder Judiciário. E o Direito se coloca em disputa pelas forças sociais como salvaguarda e normalizador de condutas. A questão que se coloca é: categorias em debate, como o gênero, na perspectiva ora trabalhada, ou ainda as inúmeras e inusitadas formas de construção familiar, como as uniões poliafetivas, as formas de convivência dos pais separados com os filhos, são mesmo passíveis de normatização ou normalização?

Em primeiro lugar, cumpre atentar para o termo "regulação", que pode sugerir a concretização de um processo de legitimação de institucionalização pelo qual os indivíduos são tidos como normais. Leis, regras e política ditas inclusivas de certa forma trabalham no sentido de "legalizar pessoas", ou dito de outra forma, revestirem-nas de normalidade e, portanto, suscetíveis ao abrigo do Direito.

A regulação, em grande medida, contribui para a construção ou estabilização de standarts, de padrões desejáveis, às denominadas regularidades que, como já alertava Foucault (1999), conduzem à estratégias de disciplina e organização de relações de poder.

As normas acabam por estabelecer e delimitar uma normalização. No direito de família, por exemplo, assiste-se à derrocada do casamento como modelo único, já que a Constituição da República de 1988 entende como regular e legítima a família monoparental e a união estável. Só depois de árduas discussões doutrinárias acerca da interpretação constitucional do artigo 226 - que trata expressamente dessas outras formas de família - é que se estabeleceu então, sem controvérsias, que esse rol seria exemplificativo e não haveria ilegitimidade em outras formas de família. Ainda assim, a questão não se pacificou, tendo sido necessária a manifestação do Supremo Tribunal Federal sobre a possibilidade ou não de ser atribuído status de família às ditas uniões homoafetivas.

A partir dessa decisão, o Conselho Nacional de Justiça "permitiu" a lavratura de escrituras de uniões estável aos pares do mesmo sexo. Ainda assim, e, por óbvio, nem todas as possíveis formas de família puderam ser "legitimamente" reconhecidas - referência específica à união poliafetiva, caso relatado no início do trabalho. Ora, se os interessados levarem o pleito de reconhecimento como família aos tribunais, e, se estes, seguindo a tendência de ampliar ou reconhecer as múltiplas realidades que se apresentam, posicionarem-se favoravelmente a atribuição de efeitos jurídicos a esses núcleos, pergunta-se: e amanhã? Qual realidade ou pretensa forma de família ficaria fora da regulamentação? Ou seja, a regulação 
em forma de estabilização de condutas é improdutiva, será sempre insuficiente e atende sempre a imperativos de poder que decompõem vulnerabilidades e historicidades.

Como outro exemplo, há quem comemore algumas decisões do Superior Tribunal de Justiça que legitimam as adoções por casais homossexuais ou, ainda, que comemore a possibilidade de adoção unilateral por pessoa solteira instituída por lei. Ora, esse tipo de norma apenas reforça, ainda que de forma mascarada, o ideal: que a adoção seja realizada por par heterossexual casado. O que se deveria prestigiar é adoção per se: a possibilidade de dar um lar a uma criança que se encontra institucionalizada ou em condição de vulnerabilidade junto à família biológica. Não há transgressão e não haveria sequer que se questionar a adoção por pessoas que não se enquadram nessa situação considerada ideal. O que houve ao longo da história foi a formação estereotipada do casal adotante ideal.

A norma, como já advertiu Foucault, não admite o exterior, localiza e delimita espaços de atuação do sujeito, confina de tal modo a criar uma reproduzir uma categoria ou uma natureza comum a seus destinatários, e ao fazê-lo cria comparações (com aqueles que não se aplicam em suas hipóteses) e, comparações são naturalmente excludentes. A norma não tem capacidade para regular todos os fenômenos sociais, porque ela própria enfrenta limites internos nas regulações. Acabam por se constituir em espaços circunscritos que cerceiam a dialética, pois expressam determinadas relações de referência com o próprio grupo que regulamenta a não permitir referências externas (EWALD, 1991, p. 173).

Certo é que o Direito está sempre sob tensão, disputado pelas forças sociais e administrado pelos agentes do Estado, cada vez mais controlador e invasivo. Como relata Rodriguez (2009), o Estado de Direito dispõe de duas gramáticas básicas para lidar com as demandas sociais: a "gramática normativa" e a "gramática da autorregulação" ou, em uma formulação mais recente, a gramática da "regulação estatal" e a gramática da "regulação social".

É um momento de rompimento, ponto de viragem (Umbruch), de fim de uma era e de início de algo novo que desponta, mas que ainda não foi devidamente identificado ou rotulado, de uma crise científica do Direito e de outras ciências (SANTOS, 2000, p. 76). Por certo, há que se desvestir-se do familiarismo falocêntrico, universalisante e repressivo. Para Barroso (2006, p. 4), “entre luz e sombra, descortina-se a pós-modernidade; o rótulo genérico que abriga a mistura de estilos, a descrença no poder absoluto da razão, o desprestígio do Estado; [...] uma época pós-tudo: pós-Marxista, pós-Kenseniana, pós-Freudiana”.

Vive-se certamente num novo mundo centrado não mais na figura do pai, mas onde certamente também não há predomínio da mulher. Há um convite aberto à reflexão sobre a dualidade de gêneros que, colocada em cheque, possibilita o gozo avassalador que repercute 
das mais diversas maneiras, conduzindo até mesmo à diferentes adicções - sexo, drogas, trabalho, consumo, comida.

Abaladas as estruturas de um pensamento jurídico que elevava a neutralidade e a objetividade à categorias intocáveis, cabe reconhecer que o Direito, ao enunciar-se em normas, alinha significados, significantes, necessidades impulsionais, desejos. O estudo do sistema normativo, assim, reclama uma aproximação da realidade que o circunda e das subjetividades que lhe são inerentes.

Não há ainda conclusões definitivas entre regulação e não regulação. Certo é que qualquer processo de normatização deve considerar as contradições, interesses e demandas dos atores sociais emergentes (WOLKMER, 2004, p. 89). Por enquanto, diversas famílias estão relegadas a uma zona cinzenta do Direito, situação agravada por dificuldades cotidianas como morte, doenças, separação, filiação. Mas, sem dúvidas, a regulação dos relacionamentos familiares vem sofrendo, mais que quaisquer outros institutos jurídicos, contínuas e relevantes transformações (PANNARALE, 2007, p. 16).

\section{CONCLUSÃO}

As perspectivas futuras indicam que as famílias poliafetivas, assim como tantas outras, reclamam por reconhecimento. Desafia-se o tênue equilíbrio entre regulação e não regulação. A afirmação majestosa de uma soberania familiar monolítica e inquebrantável encontra-se decaída. Desnudou-se à realidade de um mundo multifacetado, mas violentamente unificado, que precisa eliminar fronteiras confortáveis do Direito, a fim de não condenar o ser humano à horizontalidade devastadora mas, sim, a incitar a construção incessante de subjetividades próprias, de forma a restaurar o equilíbrio entre o um e o múltiplo (a harmonia entre o indivíduo, o grupo familiar escolhido e a sociedade), instaurando uma ordem simbólica necessária à formação da identidade.

Certo é que a família é um núcleo valorativo do qual todos parecem querer participar. Assim, as uniões familiares, longe de seus ornamentos únicos da sacralidade, são mais que nunca eletivas, por vezes fruto de um amadurecimento reflexivo, fulcradas em laços de afeto ou apenas em vínculos que atendem a critérios de utilidade ou conveniência. Pouco importa! Resta ao Direito garantir de modo igualitário cada escolha, cada construção, cada núcleo, ainda que aos olhos dos mais desconfiados pareçam bizarros ou inadequados.

Os estudos propostos por Foucault e Butler, ao revelarem que a sexualidade é penetrada por relações de poder e absorvida pelo exercício da política, indicam o árduo caminho ao reconhecimento das uniões poliafetivas. 
Para compreender o cenário familiar, deve-se estar consciente da cartografia da

transdiciplinariedade e de que não há purismo e absolutismo conceitual. É hora de romper com a sombra denegatória de direitos, que um dia encobriu os filhos ilegítimos, a mulher não casada, a união homafetiva e, que hoje, paira sobre as famílias poliafetivas. O direito de família há de superar barreiras de exclusão e redirecionar os convites de ingresso à titularidade de direitos e obrigações, afastando as forças prejudiciais e estigmatizantes de valores calcados em juízos depreciativos, atrasados e equivocados.

\section{REFERÊNCIAS}

AYTO, John. Dictionary of Word Origins. New York: Arcade, 1990.

BARROSO, Luís Roberto. A Nova Interpretação Constitucional: ponderação, direitos fundamentais e relações privadas. 2 ed. Rio de Janeiro: Renovar, 2006.

BIRMAN, Joel. Entre cuidado e saber de si-sobre Foucault e a psicanálise. Rio de Janeiro: Relume-Dumará, 2000.

BORNSTEIN, Kate. Gender Outlaw. New York: Routledge, 1994.

BUTLER, Judith. Regulações de gênero. Cad. Pagu, Campinas, n. 42, p. 249-274, jun. 2014. Disponível em <http://www.scielo.br/scielo.php?script=sci_arttext\&pid=S0104$83332014000100249 \& \operatorname{lng}=$ pt\&nrm=iso $>$. Acesso em 16 jan. 2016.

CRANNY-FRANCIS, Anne; WARING, Wendy; STAVROPOULOS, Pam; KIRBY, Joan. Gender Studies: Terms and Debates. New York: Palgrave Macmillan, 2003.

CUNHA, Eduardo L. Entre o assujeitamento e a afirmação de si. Cadernos de Psicanálise, SPCRJ, v.18, n.21, p.167-180, 2002.

EWALD, François. Norms, Discipline, and the Law. In: POST, Robert (ed.). Law and the Order of Culture. Berkeley: University of California Press, 1991.

FOUCAULT, Michel. The Subject and Power. In: DREYFUS, Hubert; RABINOW, Paul (ed.). Michel Foucault - Beyond Structuralism and Hermeneutics. Chicago: University of Chicago Press, 1982. 
FOUCAULT, Michel. A história da sexualidade I: a vontade de saber. Tradução de Maria Thereza da Costa Albuquerque e J. A. Guilhon Albuquerque, 13 ed. Rio de Janeiro: Edições Graal, 1999.

GAGLIANO, Pablo Stolze. Direitos da(o) amante - na teoria e na prática (dos Tribunais). 2008. Disponível em: 〈http://lfg.jusbrasil.com.br/noticias/64492/direitos-da-o-amante-nateoria-e-na-pratica-dos-tribunais-prof-pablo-stolze-gagliano>. Acesso em: 15 jan. 2016.

GERMON, Jennifer. Gender: a genealogy of an idea. New York: Palgrave Macmillan, 2009.

IRIGARAY, Luce. This Sex which is Not One. Ithaca: Cornell University Press, 1985.

LACAN, J. Duas notas sobre a criança. In: Opção Lacaniana - Revista Brasileira internacional de psicanálise, n. 21, São Paulo: Edições Eólia, abr. 1998.

LOURO, Guacira Lopes. Gênero, sexualidade e educação: uma perspectiva pósestruturalista. Petrópolis: Vozes, 1997.

MOREIRA, Jacqueline de Oliveira. Mídia, espetáculo e sociedade de consumo. In: CRP-04 (org.), Subjetividade(s) e sociedade: contribuições da Psicologia. Belo Horizonte: Casa do Psicólogo, 2009, p. 89-102.

MOREIRA PINTO, João Batista. As diferentes concepções do sujeito e suas inter-relações com o direito. Revista Veredas do Direito. v.1, n.2, p. 81-90, Belo Horizonte, 2004.

PANNARALE, Luigi. Sexo do direito: tipos de família e regulamentação jurídica na Itália e na Europa. Revista Veredas do Direito. v.4, n.7, p. 09-28, Belo Horizonte, 2007.

PISCITELLI, Adriana Gracia. Re-criando a categoria mulher? In: ALGRANTI, Leila Mezan (Org.). A prática feminista e o conceito de gênero. Campinas: IFCH/UNICAMP, 2002, v. 48, p. $7-42$.

RODRIGUEZ, José Rodrigo. Fuga do Direito: contemporâneo a partir de Franz Neumann. São Paulo: Saraiva, 2009.

SANTOS, Boaventura de Souza. A crítica da Razão Indolente: contra o desperdício da experiência. São Paulo: Cortez, 2000. 
SARZ, Luiz Alberto. Mídia e produção de subjetividades: questões da cultura. In: Mídia e psicologia: produção de subjetividade e coletividade. O bárbaro frente ao espelho. Brasília: Conselho Federal de Psicologia, 2009. p. 91-98.

WOLKMER, Antônio Carlos. As necessidades humanas como fonte insurgente de direitos fundamentais. Revista Veredas do Direito. v.1, n.3, p. 85-92, Belo Horizonte, 2004. 